\title{
Credence: A Belief-First Approach
}

\author{
Andrew Moon ${ }^{1 \star}$ and Elizabeth Jackson ${ }^{2,3}$ \\ 1Virginia Commonwealth University, Richmond, VA, USA, 'School of Philosophy, Australian National University, Canberra, \\ Australia, and ${ }^{3}$ Department of Philosophy, Ryerson University, Toronto, ON, Canada \\ *Corresponding author. Email: andrewmoon616@gmail.com
}

\begin{abstract}
This paper explains and defends a belief-first view of the relationship between belief and credence. On this view, credences are a species of beliefs, and the degree of credence is determined by the content of what is believed. We begin by developing what we take to be the most plausible belief-first view. Then, we offer several arguments for it. Finally, we show how it can resist objections that have been raised to belief-first views. We conclude that the belief-first view is more plausible than many have previously supposed.
\end{abstract}

Key Words: Credence; belief; confidence; epistemic probability; epistemic modals; animal concepts

\section{Introduction}

Sally believes that there are ducks. Sally withholds belief that there are an even number of ducks. Sally disbelieves that ducks are mammals. Many epistemologists focus on these three attitudes: belief, withholding belief, and disbelief.

Sally also has a high degree of confidence that there are ducks and a smaller degree of confidence that there are an even number of ducks. She has little to no confidence that ducks are mammals. Many epistemologists focus on degrees of confidence, or what are commonly called "credences." Unlike coarse-grained belief attitudes, credences are more fine grained. You can withhold belief that there are an even number of ducks and that my six-sided die will land either 2 or 3 , while having a higher credence in the former proposition than the latter.

We assume in this paper that the mundane claims made in the above two paragraphs are true. More explicitly, we assume the following: that people commonly believe (or withhold belief from) propositions, and that people have varying credences (or degrees of confidence) in propositions. ${ }^{2}$ Our aim here is to explore how those two types of mental states relate. Some philosophers deny these assumptions. Eliminativists argue that there are no beliefs or credences (Churchland 1981 and Stich 1996). Some only deny beliefs exist but affirm credences exist (Jeffrey 1970) and others only deny credences exist but affirm beliefs exist (Holton 2014 and Horgan 2017). Some, like Moss (2018), deny that we believe propositions (where "proposition" is defined as the fundamental bearer

\footnotetext{
${ }^{1}$ Following current literature, we will use "credence" to mean something like degree of confidence, and we will use the terms "confidence" and "credence" interchangeably. For argument that this is current convention, see Moon (2019, 276-77). Some people use "degrees of belief" talk to refer to degrees of confidence or credences. For the most part, we'll not use this talk since there's dispute about whether beliefs come in degrees (Moon 2017). Note also that we are not assuming that credences are necessarily probabilistically coherent, although coherence might be a requirement for rational credence. Finally, we take these credences to be attitudes of the person, not subpersonal representations; see footnote 46.

${ }^{2}$ For an argument that we do sometimes flat-out believe propositions, see Archer (2018).

(C) The Author(s) 2020. Published by Canadian Journal of Philosophy.
} 
of truth and falsity $)^{3}$ and think that we only believe sets of probability spaces. ${ }^{4}$ These are all potential ways to resolve the belief-credence debate. However, in light of the above assumptions, this paper is about how one's believings (and withholdings) in propositions relate to one's credences in propositions.

Recently, three views on the relationship between belief and credence have emerged. ${ }^{5}$ The first is a "credence-first" view, on which credence is the fundamental attitude. Credence-firsters reduce the categorical attitude of believing $p$ to the degreed attitude of having a high credence in $p .{ }^{6}$ A natural version of the credence-first view is the "threshold view." This view is described by Mark Kaplan $(1996,91)$ with the helpful analogy of a millionaire. To be a millionaire just is to have a sufficient degree of wealth. Analogously, on the threshold view, having a belief just is having a sufficiently high credence.

The second is "dualism," on which neither belief nor credence is more fundamental; each attitude is ontologically independent. This view is more complex, but proponents of dualism maintain it can nonetheless better explain our mental lives. On some versions of dualism, belief and credence are distinct epistemic tools that serve different purposes. For example, we use beliefs in low-stakes scenarios when we can assume certain propositions and still reason accurately enough for our aims. It would be natural to just believe that a colleague, Rachel, is in the office because we saw her coat, and rely on this belief if a friend casually asked if she is in today. On the other hand, we use credences in high-stakes cases, where precision and accuracy in reasoning are especially important. Suppose the police are investigating a murder and require a list of everyone in the office that day. Since we only saw her coat, we would fall back on a more precise credence, which we would express by saying that we were pretty confident, but not absolutely certain, that she was there. Thus, when stakes are high, we reason using credences rather than beliefs. Dualism has been growing in popularity, with both philosophical and psychological arguments proposed in its favor. ${ }^{8}$

The third is a "belief-first" view, on which belief is the fundamental attitude and credence is a species of belief. A natural version of this view says that one's credence that $p$ is directly proportional to the degree of likelihood that $p$ is believed to have. For example, a belief firster might think that a credence of 0.5 that the coin will land heads up reduces to a belief with the content that the probability the coin will land heads up is 0.5 .

\footnotetext{
${ }^{3}$ See Merricks $(2015,21-23)$ for more on this common understanding of propositions.

${ }^{4}$ Moss argues for what she calls "a fairly radical conclusion, namely, that probabilistic contents should ultimately replace propositions as the fundamental contents of belief" $(2018,14)$. She notes that if we define "proposition" as whatever is the object of belief, then, on her view, we do believe propositions $(2018,15)$. In the context of this discussion, this is neither here nor there. This paper's assumption is that we do commonly believe whatever is the fundamental bearer of truth and falsity; nothing stands or falls on whether we use the word "proposition" for that thing. For criticism of Moss's view, see Moon (2019, 288; specifically endnote 39).

${ }^{5}$ Jackson (2019a) argues that many important epistemological issues hinge on which of these views is correct.

${ }^{6}$ Discussions and defenses of the credence-first view include Levi (1991), Foley (1993, 2009), Maher (1993), Bouvens and Hawthorne (1999), Christensen (2004), Weatherson (2005), Douven and Williamson (2006), Ganson (2008), Sturgeon (2008, 2010, 2020), Frankish (2009), Smith (2010), Wedgwood (2012), Clarke (2013), Leitgeb (2013), Pettigrew (2015), Greco (2015), Lee (2017), and Dorst (2019).

${ }^{7}$ The threshold view is also discussed, among other places, in Foley $(1993,2009)$ and Sturgeon $(2008,2010)$. As Julia Staffel pointed out in conversation, you could have a threshold view that is not credence-first. For example, consider the following belief-first view: having a high credence in $p$ just is believing $p$ is sufficiently probable. One could affirm both this and the threshold view if they affirmed that believing $p$ is sufficiently probable entails believing $p$. See Weisberg (Forthcoming, n8).

${ }^{8}$ Discussions and defenses of dualism include Pollock (1983); Adler (2002); Frankish (2004); Hawthorne (2009); Sosa (2011); Friedman (2013); Ross and Schroeder (2014); Buchak (2015); Littlejohn (2015); Carter, Jarvis, and Rubin (2016); Staffel (2017); Jackson (2018, 2019a, 2019b, Forthcoming), Weisberg (2013, Forthcoming), and Collins (Forthcoming). The example is from section 4.2 of Jackson (2019a).
} 
This third view is the focus of this paper. While the current belief-credence literature contains many interesting defenses of credence-first and dualist views, belief-first approaches are normally discussed only briefly and then quickly dismissed because of objections. ${ }^{9}$ There are few plausible defenses of belief-first approaches in the literature. Our aim is to fill this lacuna. ${ }^{10}$

In section 2, we develop what we take to be the most plausible version of the belief-first view. In section 3, we build a prima facie case for this belief-first view. Finally, in section 4, we address two prominent objections to it.

\section{Belief-first explained}

\section{2.a The view}

Let " $M$ " be a variable ranging over epistemic modal operators such as "very probably," "it might be that," and "it's 0.3 likely that," and let " $X$ " be a variable ranging over numbers and intervals between 0 and 1 inclusive. We defend the following:

Belief-First: For $S$ to have $X$ degree of credence that $p$ just is for $S$ to believe $M p$ (where $X$ and $M$ correspond to each other).

This entails:

Biconditional: $S$ has $X$ degree of credence that $p$ if and only if $S$ believes $M p$ (where $X$ and $M$ correspond to each other). ${ }^{11}$

We use the term "belief-first view" to pick out any view according to which credences just are beliefs of a certain sort. We use the terms "Belief-First" and "Biconditional" as names that pick out the above two views. Belief-First goes beyond Biconditional by making a claim about the nature of credence. Biconditional only makes a claim about what is coextensive across possible worlds.

The correspondence relation between $X$ and $M$ is best grasped by appeal to examples. For Fred to have 0.6 confidence that it will rain is for Fred to believe it is 0.6 likely that it will rain. For Fred to have a high credence that it will rain is for Fred to believe that it is likely that it will rain. And for Fred to have a low credence that it will rain is for Fred to believe that it is unlikely that it will rain. Credences need not be precise. Fred's high credence that it will rain can be imprecise as long as the high probability that Fred attributes to it will rain is also imprecise.

" $M$ " can range over nonprobabilistic modal operators. A modal operator like "possibly" or "might" will correspond with "some nonzero," and a modal operator like "impossibly" will correspond with "a zero." Suppose Fred thinks that it might rain. Then Fred has some nonzero credence that it will rain. Or suppose Fred thinks that it's impossible that it will rain. Then Fred will have a zero credence that it will rain. Suppose Fred has both some nonzero credence that it will rain and a 0.6 credence that it will rain. Then Fred will both believe that it's possible that it will rain and believe that it is 0.6 likely that it will rain. These examples illustrate the correspondence relation between $X$ and $M$.

Now that we've clarified the basic tenets of the view, it is worth briefly discussing how our paper fits in with existing discussions of belief-first views in the literature. As noted earlier, belief-first views have few sustained defenses and are often mentioned only to be objected to and dismissed

\footnotetext{
${ }^{9}$ Some authors who discuss belief-first sympathetically include Harman (1986, 2008), Plantinga (1993a, chap. 1), Lance (1995, sec. 4), Schiffer (2003, 200), Holton (2008, 2014), Weisberg (2013, sec. 3.1), Easwaran (2015), Dogramaci (2018), Moon (2018), and Kauss (Forthcoming).

${ }^{10}$ One author of this paper is a belief-firster, but the other is a dualist. Nonetheless, we agree that many recent objections to belief-first views fail and that belief-first views are dismissed too quickly.

${ }^{11}$ These formulations draw from Moon $(2019,274)$.
} 
(e.g., Christensen 2004; Staffel 2013; Moss 2018). Other authors discuss them sympathetically, but don't defend them at length (e.g., Plantinga 1993a, chap. 1; Weisberg 2013; Dogramaci 2018). Other authors defend the view that belief is more fundamental than credence, but do not maintain that credences reduce to beliefs about epistemic modals in particular (e.g., Lance 1995; Holton 2008, 2014; Harman 1986, 2008; Horgan 2017). Further, some of these philosophers (especially Holton and Horgan) might be better classified as credal eliminativists, as they express skepticism about the existence of credences altogether.

Two recent belief-first views are noteworthy. According to Kauss (Forthcoming), one's credence in $p$ reduces to one's tendency to believe $p$. This view is notably different from ours in several ways. For one, credences don't reduce to features of the content believed. Further, on Kauss's view, belief is credence 1; our belief-first view does not have this controversial (and, to some, unwelcome) consequence. Easwaran (2016), on the other hand, reduces credences to the overall pattern of an agent's beliefs (plus the agent's weighing of the value of true belief and the disvalue of false belief) an interesting suggestion, but clearly different than our view on which each credence reduces to a specific corresponding modal-belief. ${ }^{12}$

\section{2.b Epistemic modality and some criticisms}

We say that " $M$ " ranges over epistemic modal operators. We will clarify what this means, since some critics have said that belief-first views fail because there is no appropriate meaning of "probability" in their formulations. For example, Julia Staffel writes,

No matter how we spell out what we mean by probability-objective probability, evidential probability, frequency, etc.-it is always possible for a subject to have a degree of confidence in some proposition $p$, yet be uncertain what probability to assign to $p$, and thus to lack the corresponding outright belief. $(2013,3537)$

Our belief-first view helps avoid this criticism by expanding the range of epistemic modals beyond probabilities. For example, one need not be certain about what probability to assign $p$ in order to have a credence in $p$; as we said above, merely believing that it might rain suffices for having some nonzero credence that it will rain. (Staffel's objection is addressed in more detail in section 4.c.)

Another criticism comes from Christensen (2004). He gives the case of someone who has a degree of confidence of 0.4 that Jocko cheated on Friday's test and suggests some belief-first interpretations of this case. If "probability" is understood as subjective probability, then "probability" will itself pick out a credence. Then the belief-first view would implausibly take credences to be beliefs about credences. Christensen goes on:

On the other hand, if we understand probabilities in some more objective way, we risk attributing to the agent a belief about matters too far removed from the apparent subject matter of her belief. For example, if probabilities are given a frequency interpretation, we will interpret our agent as believing something like: Within a certain specific reference class ... cheating took place $4 / 10$ of the cases. (19)

Christensen thinks it is implausible that one must have even an implicit thought about reference classes to have a 0.4 credence that Jocko cheated. He concludes,

these examples serve well enough to show how unnatural it is to identify an agent's having a certain degree of confidence in a particular proposition with that agent's having an all-ornothing belief about some nonbelief-related proposition about objective probabilities. (20)

\footnotetext{
${ }^{12}$ Thanks to a referee for encouraging us to make explicit how our belief-first view differs from others in the literature.
} 
We agree with Christensen that belief-first views that appeal to subjectivist and frequentist interpretations of probability fail for the reasons he gives.

We use "probable" and "possible" in a way that avoids Christensen's criticisms. It is the sense that is both often referred to by epistemologists with the terms "epistemic probability" and "epistemic possibility" and also commonly referred to in ordinary English. ${ }^{13}$ Suppose Fred randomly considers the proposition that $567 * 123=69,741$. Before calculating the equation, he says, "It's very unlikely, but it's possible that it's true"; after calculating it, he says, "It is very likely that $567 * 123=69,741$." The sort of probability and possibility expressed in these sentences is how we understand the modality in Biconditional and Belief-First.

The example distinguishes our use of the expressions "epistemically possible" and "epistemically probable" from more objective interpretations of probability, such as the frequency interpretation, on which necessary truths such as $567 * 123=69,741$ always have the highest degree of likelihood. But surely there is a clear sense of "possible" and "unlikely" in ordinary English according to which Fred's statements are both warranted and true. This is the type of probability with which we are concerned. $^{14}$

Here are some roughshod analyses of epistemic possibility and probability.

Knowledge-Based Analysis: $p$ is possible (or probable) for $S$ if and only if $p$ is consistent with (or well supported by) $S$ 's knowledge. ${ }^{15}$

Evidence-Based Analysis: $p$ is possible (or probable) for $S$ if and only if $p$ is consistent with (or well supported by) $S$ 's total evidence. ${ }^{16}$

Ideal-Agent-Based Analysis: $p$ is possible (or probable) for $S$ if and only if, $S$ would have some nonzero degree of confidence (or a moderately high confidence) that $p$ if $S$ were an ideal epistemic agent in $S$ 's epistemic situation. ${ }^{17}$

Function-Based Analysis: $p$ is possible (or probable) for $S$ if and only if, $S$ would have some nonzero degree of confidence (or a moderately high confidence) that $p$ if $S$ 's cognitive faculties were functioning properly with the aim of producing true belief. ${ }^{18}$

We will not assume the truth of any of these analyses. They, combined with the cases mentioned above, are meant to help readers grasp the concepts of epistemic probability and possibility (combined, epistemic modality) that we employ in our belief-first view.

Now, we are not concerned so much with epistemic possibility and probability themselves, but with a kind of belief about them, which we call "modal-beliefs." One has a modal-belief that $p$ when one believes $M p$, where " $M$ " ranges over epistemic modal operators. In the earlier example, Fred believed that it is likely that $567 * 123=69,741$. Suppose you are wondering where Sally is and you say, "She's probably at the mall," thereby expressing your belief that it's probable that she is at the mall. Modal-beliefs are common and relatively easy to come by. An unsophisticated, relatively young child could believe that Sally is probably at the mall, might be at home, and could not be at the

\footnotetext{
${ }^{13}$ See Hawthorne and Stanley (2008, 584), Smithies (2012, 274), Moon (2018, 1839-40), Sturgeon (2020, chap. 9), as well as the references in the next five footnotes.

${ }^{14}$ This point is based on Plantinga's (1993a, 150-51) objection to theories of logical probability serving as theories of epistemic conditional probability.

${ }^{15}$ This knowledge-based derived from Stanley $(2005,128)$. For other knowledge-based accounts, see DeRose (1991), Williamson (2000, chap. 10), Huemer (2007), and Hawthorne and Stanley (2008). Epistemic logicians also commonly define epistemic possibility in terms of knowledge. See the influential Kratzer (1977).

${ }^{16}$ This evidence-based account is derived from Dougherty and Rysiew $(2009,127)$.

${ }^{17}$ This ideal-agent-based account is derived from Joyce $(2002,73)$.

${ }^{18}$ This proper-function-based account is derived from Plantinga (1993b: 168). See Otte (2006) for criticism.
} 
North Pole. ${ }^{19}$ Note also that even if one of the above analyses is true, it does not follow that one must believe that each of the components in the analysans is instantiated in order to believe the analysandum is instantiated. For example, even if the ideal-agent-based analysis is true, a child could still believe Sally might be home without having the belief that he would have a nonzero credence that Sally is home if he were an ideal epistemic agent.

Let us return to Christensen's criticism. He says that you have a 0.4 credence that Jocko cheated. Now, there are two possibilities that Christensen might be asking us to imagine. He might merely be asking us to imagine that you have a moderately small degree of confidence that Jocko cheated. Alternatively, he might be asking you to imagine that you have a precisely 0.4 degree of confidence.

Consider the first option. On a natural reading of that case, you will have seen some evidence of Jocko cheating, which makes you suspicious of him. This will explain how you could have a moderately small degree of confidence that Jocko cheated. But on this reading of the case, it will also be natural to think that you believe there's a moderately small (epistemic) likelihood that Jocko cheated. So, on this first option, there is no clear counterexample to Biconditional.

Consider the second option, on which you have precisely a 0.4 confidence that Jocko cheated. It is hard to think of an ordinary case in which you would have precisely 0.4 confidence. For a normal human's psychology, the evidence would result in your just having a moderately low confidence that he cheated. Now, we could fill in the case so that it is natural to think that you have 0.4 confidence. Suppose you know that Jocko belongs to some class of humans, you know that precisely $4 / 10$ of that class will cheat, and you know of no other relevant information. In this case, it is plausible that you have a 0.4 confidence that Jocko cheated. But if the case is spelled out this way, you would believe that there is a 0.4 chance that Jocko cheated, which would correspond to your believing that there is a 0.4 epistemic probability that Jocko cheated. ${ }^{20}$ So, on this second option, there's again no counterexample to Biconditional.

\section{2.c Semantics of epistemic modals: descriptivism and credal expressivism}

Recently, a debate has emerged in the semantics of epistemic modals between "descriptivists" and "credal expressivists." It is natural to think that sentences such as "Fred might be happy" or "Fred is probably happy" express propositions, respectively, the proposition that Fred might be happy and the proposition that Fred is probably happy. Those who hold this view are called "descriptivists."

"Credal expressivists" deny descriptivism. They think that epistemic modals such as "Fred might be happy" and "Fred is probably happy" do not express propositions. Rather, they express some attitude of the speaker toward the proposition that Fred is happy. One common version of credal expressivism includes two components: (i) to assert " $M p$ " is to express one's $X$ degree of credence toward $p$ and (ii) one believes $M p$ if and only if one has $X$ degree of credence that $p$ (i.e., Biconditional). ${ }^{21}$ This is similar to moral expressivism, which affirms that " $X$ is wrong" does not express the proposition that $\mathrm{X}$ is wrong and instead expresses some attitude of the speaker toward $X$. One common version of moral expressivism also includes two components: (i) to assert " $X$ is wrong" is to express one's negative attitude toward $X$ and (ii) one believes $X$ is wrong if and only if one has a negative attitude toward $X .^{22}$

How is this relevant to our topic? Suppose descriptivism is true. Then, sentences of the form, " $S$ believes that $M p$ " ascribe to $S$ a belief with the propositional content $M p$. Thus, modal-beliefs are

\footnotetext{
${ }^{19}$ Many think that epistemic possibility ascriptions are context sensitive. This might make some people think that Biconditional implies that "is confident" is context sensitive. But this does not follow. Although " $p$ is likely" might be context sensitive, it does not follow " $S$ believes that $p$ is likely" is context sensitive. For more on this, see footnote 23.

${ }^{20} \mathrm{We}$ are assuming here that people's beliefs about epistemic probabilities follow their beliefs about objective chances. See footnote 31 for more discussion of this point.

${ }^{21}$ Our explication of credal expressivism draws from Yalcin (2011), Moon (2019), and Lennertz (Forthcoming).

${ }^{22}$ See Lennertz (Forthcoming) for an excellent exploration of the comparisons between moral and credal expressivism.
} 
beliefs with a certain type of propositional content. Now, according to Belief-First, for $S$ to have $X$ degrees of credence that $p$ just is for $S$ to believe $M p$. It is then natural to understand credences to just be beliefs with a certain propositional content. This would be a belief-first view according to which credence is a species of belief, and belief is more fundamental. ${ }^{23}$

This nice story goes amuck if credal expressivism is true. On credal expressivism, for $S$ to believe $M p$ is not for $S$ to believe a proposition. We can thus no longer say that a credence that $p$ just is a belief that $M p$, where the belief that $M p$ is itself a belief with $M p$ as its propositional content. Given an assumption of our paper that the contents of beliefs are propositions, it turns out that modalbeliefs are not actually beliefs. On this picture, then, credences do not reduce to propositional, modal-beliefs. So, Belief-First is inconsistent with credal expressivism. ${ }^{24}$

(Interestingly, if we drop the assumption that the objects of beliefs are propositions, then credal expressivism is compatible with Belief-First. Suppose the objects of beliefs were not propositions, but some other sort of thing: $R$. Suppose also that modal-beliefs were a type of belief [with the objects of modal-beliefs being $R$ ]. Then, Belief-First could still be true, where credences would just be these modal-beliefs, which are really beliefs [with contents $R$ ]. Hence Belief-First is compatible with credal expressivism if we drop our assumption that beliefs are propositional. $)^{25}$

The debate between credal expressivists and descriptivists is challenging and complex. ${ }^{26}$ In this paper, we will proceed as if descriptivism is true. We think this is permissible for two reasons. First, even those who already affirm descriptivism are not always inclined toward a belief-first view, and many objections to the belief-first view we defend are independent of the expressivist-descriptivist debate. Our aim is to address those concerns. Second, philosophy requires a division of labor; it would be unreasonable to think that the complex descriptivist-expressivist debate must be resolved before writing this paper. However, those who do not like our assumption can just take us to be defending the conditional claim-if descriptivism is true, then Belief-First is true-which is an interesting thesis that moves discussion forward. That said, since many credal expressivists affirm Biconditional, they should still be interested in many of the arguments for Biconditional in section 3 , since those arguments are independent of the expressivist-descriptivist debate. ${ }^{27}$

\footnotetext{
${ }^{23}$ Suppose the above evidence-based analysis of epistemic modality is true. Then for $S$ to believe probably- $p$ will be for $S$ to believe $\mathrm{p}$ is probable, given S's evidence. But suppose $S$ asserted, "Probably-p!" Depending on the context, the proposition expressed by this sentence, plausibly, will not be that $\mathrm{p}$ is probable, given $\mathrm{S}$ 's evidence, but perhaps $\mathrm{p}$ is probable given an assessor's evidence or $\mathrm{p}$ is probable given the hearer's evidence or something else. (For example, suppose a spy hears a speaker say, "There is probably no spy here!" Intuitively, the spy can correctly say that sentence (and thus the proposition it expresses) is false. This indicates that the proposition expressed is about what's probable given the spy's evidence, not the speaker's evidence.) Descriptivists have a hard time nailing down whose evidence determines which proposition is expressed by modal sentences, and this difficulty moves some to accept expressivism (Yalcin 2011). Fortunately, we think we can avoid this thorny issue by just stipulating that the relevant proposition $S$ must believe for $S$ to have a credence is the proposition that Mp, given S's evidence. Now, if $S$ asserted, “ $M p$ !" $S$ might not succeed in expressing this proposition (depending on who's in the room), but it is that proposition that is relevant for our belief-first view. Thanks to Sinan Dogramaci for raising this concern.

${ }^{24}$ Note that credal expressivism is compatible with other belief-first views, as well as credence-first and dualist views. For example, credal expressivism is compatible with a belief-first view on which credences reduce to inclinations to believe propositions, as Kauss (Forthcoming) affirms. It is compatible with a dualist view on which modal beliefs (which are not propositional, according to the credal expressivist) are just credences, and these credences play a different functional role than propositional beliefs. It is compatible with a credence-first view on which beliefs are just high credences. Thanks to a referee for helping us see the need to clarify this point.

${ }^{25}$ Thanks to Simon Goldstein for helping us see this point. While most epistemologists think we believe propositions, as we discuss in footnote 4, Moss (2018) denies this. She is a credal expressivist, but explicitly denies Belief-First.

${ }^{26}$ For recent defenses of descriptivism, see Crabill (2013), Dorr and Hawthorne (2013), Silk (2017), and Lennertz (Forthcoming). For recent defenses of credal expressivism, see Yalcin (2011), Schnieder (2010), Swanson (2011), Rothschild (2012), and Moss (2013).

${ }^{27}$ Thanks to an anonymous referee for this point. Only Holton's empirical evidence that we reason with probabilistic contents (in section 3.a) and the argument appealing to introspection (in section 3.b) clearly assume descriptivism. The objections to our view in section 4 will assume descriptivism. Moon (2019, sec. 2) and Dogramaci $(2018,10)$ sympathetically discuss a coextensivity principle similar to Biconditional that is neutral between credal expressivism and descriptivism.
} 


\section{A case for Belief-First}

Recall our belief-first view:

Belief-First: For $S$ to have $X$ degree of credence that $p j u s t$ is for $S$ to believe $M p$ (where $X$ and $M$ correspond to each other).

\section{This entails}

Biconditional: $S$ has $X$ degree of credence that $p$ if and only if $S$ believes $M p$ (where $X$ and $M$ correspond to each other).

Although our overall goal is to defend Belief-First, we defend Biconditional alongside it. There are two reasons for this. First, Belief-First is true only if Biconditional is true, and the most common objections to Belief-First are objections to Biconditional. Second, once descriptivism is assumed, Belief-First follows very naturally from Biconditional. Hence, given descriptivism, support for Biconditional is also support for Belief-First.

We motivate Belief-First by showing how it is a simple view that can explain much of the data. First, Belief-First is beautifully simple. It posits only one fundamental doxastic attitude: beliefs. Using this one attitude, Belief-First can account for beliefs (e.g., belief that $p$ ), numerically precise credences (e.g., belief that the probability of $p$ is 0.9 ), imprecise credences (e.g., belief that $p$ is quite likely), and comparative confidences (e.g., belief that $p$ is more likely than $q$ ). Although this is not a reason to favor Belief-First over a credence-first view, which likewise posits the existence of just one fundamental doxastic attitude, it is a reason to favor it over a dualist view, which posits the existence of two fundamental doxastic attitudes. All else being equal, if Belief-First can explain what a more complex view explains, one should prefer it.

In the rest of section 3, we argue that Belief-First has great explanatory power. First, in section 3.a, we argue that modal-beliefs and credences have the same functional profile; the work done by credences can be done by beliefs in epistemic modals. Then, in section 3.b, we argue that Belief-First can make sense of particular phenomena in epistemology and philosophy of mind, such as credal degrees of precision, introspective data, why certain sentences seem inconsistent, and how credences can amount to knowledge. Section 3 constitutes a prima facie case for Belief-First. In section 4 , we respond to objections, thus providing an ultima facie case for Belief-First.

\section{3.a Same functional profile}

Much of the work done by credences can be done by modal-beliefs. Philosophers appeal to degrees of credence when describing someone who is reasoning about statistics; belief in probabilities can play the same role. More generally, we assign a person a credence when she is undergoing probabilistic or Bayesian reasoning, but we could just as well ascribe to that person a belief in a probability. Decision theory traditionally takes credences as inputs, but it could just as well take beliefs about probabilities as inputs. ${ }^{28}$

Some have argued that belief that $p$ involves treating $p$ as true in one's reasoning. But when the stakes become high, we move to credence reasoning, consider additional possibilities, and no longer treat $p$ as true (recall the example of the office mate and murder from section 1 ). ${ }^{29}$ Biconditional can capture the spirit of this insight and maintain that, in these high-stakes scenarios, we are also considering and forming beliefs in probabilities or possibilities. For example, in a low-stakes scenario, we might simply believe $p$, but when the stakes become higher we might instead believe probably $\mathrm{p}$ or $\mathrm{p}$ is likely. In these sorts of cases, modal-beliefs have the same functional role that credences do.

\footnotetext{
${ }^{28}$ Similar models of how beliefs can guide action without appealing to credences have been developed by Hawthorne and Stanley $(2008)$ and Lin (2013). See Easwaran $(2015,19)$ for more discussion on this point.

${ }^{29}$ Ross and Schroeder (2014), Jackson (2019b), Weisberg (Forthcoming).
} 
Credences are, in many cases, measurable by betting behavior. Modal-beliefs are similarly measurable by betting behavior, and so Biconditional can explain why betting behavior is often a good test for measuring credences. According to the betting-behavior test, if one will pay $n$ dollars for a bet that will give $m$ dollars if $p$ is true and 0 dollars if $p$ is false, then one's credence that $p$ can be approximately measured by how close to 0 or 1 that $n / m$ is. If one believes that there is a 0.7 degree probability that $p$, then one will likely bet such odds on $p$. One's behavior will reveal the contents of one's belief and, hence, reveal one's credence as 0.7 . Or if one believes that there is a high probability that $p$, then one will likely bet high odds on $p$, and this will further reflect a high credence that $p$. Since betting behavior often accurately reflects the probabilities that we believe certain propositions to have, it also measures our credences in those propositions.

These reflections show how we can make inferences using the probability calculus. We can assign a number (or an interval between two numbers) between 0 and 1 to represent the degree that we believe a proposition is likely to be true, even when that degree is imprecise. Given Biconditional, that same number (or interval) would represent the credence that the proposition is true. We can then plug those numbers into formulas in the probability calculus to help us infer what our credences should be in other propositions. For instance, I might believe that $p$ is likely and so assign the degree of probability that $p$ the number 0.75 . I might believe that $q$ is very likely and so assign the degree of probability that $q$ the number 0.90 . A standard formula in probability theory is $P(p \& q)=P(p)+\mathrm{P}(q)$, when $p$ and $q$ are probabilistically independent. Suppose I know that they are probabilistically independent, and I conclude that $P(p \& q)=0.675$. Correspondingly, my credence toward $p \& q$ can be represented by 0.675 ; it will be moderately high. So, Biconditional allows for us to use the probability calculus to make inferences.

Furthermore, as Holton $(2014,21-5)$ points out, there is empirical evidence that when we engage in probabilistic reasoning, we reason using full beliefs with probabilistic content, rather than a mental state on which the numerical component is part of the attitude. ${ }^{30}$ It seems that to reason probabilistically, we have to reason about the probabilities and their values, and so the probability has to be in the content (and not, somehow, in the attitude). Belief-first offers a natural explanation of this: in these cases, there are just modal-beliefs, and this is reflected in our reasoning.

Thus, many of the roles for credences, e.g., roles in statistical or probabilistic reasoning, the role of altering the possibility space under consideration (e.g., when stakes change), the role of being measurable by betting behavior, and the role of enabling us to make inferences using the probability calculus, can be played by modal-beliefs. In the next section, we show how Belief-First and Biconditional can explain four phenomena in epistemology and philosophy of mind.

\section{3.b Belief-First's explanatory power}

First, Biconditional explains how our credences can vary in their degrees of precision. If Grace believes that $\mathrm{p}$ is very likely, she might not have a belief with a content that attributes a numerically precise probability, just as one might not have a belief with a content that attributes a numerically precise height when one believes that Mike is very tall. In such a case, Grace will just have a high (imprecise) credence that $p$. Or suppose Grace simply believes that $\mathrm{p}$ is possible but forms no specific belief about how probable $p$ is; in this case, we can conclude that Grace has some (imprecise) nonzero credence that $p$. Now, if Grace flips a coin, the likelihood that Grace believes that the coin will land heads can be represented by the number $0.5 .^{31}$ Then her credence is precise and can also be

\footnotetext{
${ }^{30}$ See also Holton (2008) and Staffel (2013).

${ }^{31}$ One might say that this is just my belief in its objective probability. Suppose that's right. Following Miller's (1966) principle (also popularly called the "principal principle" developed by David Lewis 1980) we can see that a person's epistemic probability may follow directly from their known objective probabilities. So, according to this principle, I could form a belief about the epistemic probability of the coin's falling heads once I know the objective probability.
} 
represented by 0.5 . So, it seems that the precision of our credences and the precision of the degree of probability that a proposition is believed to have vary together, and this is exactly what Biconditional predicts. ${ }^{32}$

Second, Belief-First also explains our ability to know our credences. Given Biconditional, one natural way to know our credences is by way of introspection. Now, Frank Ramsey $(1931,169)$ famously doubted our ability to introspect our degrees of belief by examining the belief s "intensity of feeling," or "feeling of conviction." He reasoned that "the beliefs which we hold most strongly are often accompanied by practically no feeling at all; no one feels strongly about things he takes for granted." For the reason Ramsey gave, an intensity of feeling does not accurately measure one's credence in a proposition.

Fortunately, there are other ways to measure credences by introspection, and Biconditional can help us see how. ${ }^{33}$ First, we sometimes have introspective access to the contents of our beliefs; from this, via the right-to-left conditional of Biconditional, we can quickly infer our credences. ${ }^{34}$ For example, a person could introspect that she believes that $\mathrm{p}$ is likely, and then infer that she is confident that $p$. It seems valid to reason, "I think that it is likely that the Lakers will win; so, I'm confident that the Lakers will win." Biconditional both explains why such reasoning is valid and also opens up ways to introspect our credences that avoid Ramsey's objection. Furthermore, cases where I don't know how confident I am in a proposition will be cases where I don't know how likely I think some proposition is. Suppose I don't know how confident I am that the Lakers will win; plausibly, I will also not know how likely I believe it is that the Lakers will win. This is all in accord with Biconditional.

Third, Biconditional can explain why various sentences sound infelicitous. Consider:

\#Fred is confident that it will rain, but he doesn't believe it is likely that it will rain.

\#Fred believes it is likely that it will rain, but he's not confident that it will rain.

The conjuncts of these sentences seem inconsistent or at least in tension. Biconditional can explain why: the sentences are inconsistent! Generally, there are issues with attempting to infer a view directly from a seeming inconsistency or tension between the conjuncts of sentences. We acknowledge that a felt inconsistency might arise from pragmatic or Gricean considerations, not because of an actual inconsistency. However, we are not attempting such an inference. The felt inconsistency is rather a bit of confirming data in favor of Biconditional. If Biconditional were true, then we would expect such sentences to feel inconsistent or in tension. They do, so we have some evidence for Biconditional.

Finally, Belief-First can explain how credences can be knowledge. Recently, Sarah Moss has drawn attention to the relationship between credences and knowledge. ${ }^{35}$ Epistemology is the study of knowledge. Credences are a popular topic among epistemologists, especially formal epistemologists. But how do credences and knowledge fit together? Traditionally, it has been assumed that belief, not credence, is the doxastic attitude that is a component of knowledge. But then it seems like the term "formal epistemology" is a misnomer since the study of (rational) credence is divorced from the study of knowledge (Moss 2013, 1).

\footnotetext{
${ }^{32}$ Note that we are not making normative claims about whether confidence should be sharp or perfectly rational agents ever have imprecise credences (as discussed by Elga [2010], White [2010], and others). We are only making descriptive claims about what degrees of confidence sometimes are for human beings.

${ }^{33}$ See also Dogramaci (2016).

${ }^{34}$ This is not to say that we have any so-called "privileged access" to the contents of our beliefs; we probably lack this ( $c f$. Gertler 2011, 77-80). Furthermore, although some philosophers, like Schwitzgebel (2008), deny the reliability of introspection in specific domains, few would deny that introspection can play a role in my knowing whether, say, I believe that $2+2=4$ or that I believe that it will probably be sunny tomorrow.

${ }^{35}$ Moss $(2013,2018)$. See also Weisberg $(2013,16-17)$.
} 
Belief-First explains how credences and knowledge fit together, even while belief is a component of knowledge. According to Belief-First, credences just are beliefs (specifically, modal-beliefs). A high credence in $p$ can be knowledge, namely, knowledge that probably $\mathrm{p}$. A credence of 0.5 that the coin will land heads can be knowledge: knowledge that the probability of the coin's landing heads is 0.5. Insofar as beliefs can be Gettiered, factive, safe, sensitive, and warranted, modal-beliefs (and, hence, credences) can as well. Thus, Belief-First explains how credences can be knowledge. ${ }^{36}$

\section{Objections to Belief-First}

There have been a few objections to belief-first views in the literature. ${ }^{37}$ Here, we focus on two of the most prominent and challenging; the first we address in two parts.

\section{4.a The oversophistication objection, pt. 1: children and animals}

Keith Frankish argues that one can have a credence without a modal-belief. He writes $(2009,77)$ :

Now it is true that we do sometimes form flat-out beliefs about probabilities . . . but it is implausible to identify our degrees of confidence ... with such beliefs. For we attribute degrees of confidence ... to individuals who lack the conceptual sophistication required for forming beliefs of this kind. We speak of children and animals having more or less confidence in something ... even though they do not possess the concepts of probability.

So, Frankish thinks that children and animals have credences without beliefs in probabilities.

In response, we first note that the possession of modal-beliefs does not require a sophisticated intellectual ability - as mentioned above, a relatively young child could believe that Sally is probably at the mall and couldn't be at the North Pole. Why would Frankish think that young children couldn't have these beliefs? Most likely, it is because he only considers difficult statistical probabilities. Like Christensen, he does not consider ordinary epistemic probabilities or even simpler epistemic modals.

On the beliefs of (nonhuman) animals, there has been considerably more disagreement over whether they have beliefs than whether humans do. ${ }^{38}$ Aristotle, Aquinas, Leibniz, and Kant all denied beliefs to animals. More recently, Davidson (1982) has argued that animals do not have beliefs because language is a requirement for belief, and animals do not have language. ${ }^{39}$ Despite such skepticism, we will assume for the sake of argument a generally nonskeptical approach to animal beliefs, taking our pretheoretic intuitions as providing at least prima facie justification for thinking that animals have beliefs.

Given that animals do have beliefs, it is not obvious that animals cannot form modal-beliefs. Seth Yalcin (2011) uses the example where his dog approaches him, and Yalcin says to his friend, "Fido thinks I might give him a bone." Intuitively, in such a case, Fido has a modal-belief. Yalcin writes, "Unless you have a particular theory of epistemic modals, I doubt you would flinch at this remark" $(2011,308)$. So, Frankish's cases are not clear counterexamples to Biconditional.

\footnotetext{
${ }^{36}$ Staffel (2019) makes a similar point.

${ }^{37}$ See Christensen (2004), Frankish (2004, 19; 2009, 76-78), Staffel (2013), and Moss (2018, 7-8). Objections from Christensen and Staffel were dealt with in section 2.b when we clarified our belief-first view. Frankish's objection is dealt with below. Moss's argument requires the falsity of descriptivism, which we are assuming to be true in this paper (see section 2.c and footnote 4 of this paper.)

${ }^{38}$ For overviews of discussions of beliefs in the philosophy of animal minds, see Beck (2012), Andrews (2015, chap. 4; 2016), and Lurz $(2009,2019)$.

${ }^{39}$ See Lurz $(2009,1-4)$ for helpful historical introduction. In a similar vein to Davidson (1982), Stich (1979) and Dummett (2010, 218-19) defend skepticism about the contents of animal beliefs.
} 
One might object that our assumption of descriptivism - that modal-beliefs are beliefs with semantic values of modal operators contributing to the contents of those beliefs-prevents us from using Yalcin's Fido example. In fact, Yalcin uses this example to argue against descriptivism. He thinks that if descriptivism is true, then "Fido thinks I might give him a bone," implies that, "Fido believes that it is left open by what he knows that I will give him a bone" $(2011,308)$. Yalcin thinks it is implausible that Fido has such second-order states of awareness. So, even if it is intuitive that Fido has a modal-belief, the case may undermine our assumption of descriptivism. ${ }^{40}$

Our reply to this objection distinguishes between two versions of descriptivism and shows that Yalcin's Fido case only threatens one version. Consider:

Complex Descriptivism: Descriptivism is true, and $S$ believes that $M p$ only if $S$ has the concept of $M$, where having the concept of $M$ requires having other second-order epistemic concepts.

The Fido case is a problem for complex descriptivism. It seems that Fido can believe that I might receive a bone without believing that it is compatible with what I know that I will receive a bone (and without having the concepts required to believe such a complex proposition).

Now consider:

Simple Descriptivism: Descriptivism is true, and $S$ believes that $M p$ only if $S$ has the concept of $M$, where having the concept of $M$ does not require having second-order epistemic concepts.

Simple descriptivism requires that Fido have the simple concept of might in order to believe he might receive a bone. And while it is plausible that Fido does not believe it is compatible with what I know that I will receive a bone, it is not so clear that Fido does not believe I might receive a bone (where we understand this as a simple descriptivist would). At least, it would be the sort of thing that would require further argument. So, the Fido case is only a problem for the less plausible complex descriptivism; it is not a problem for the more plausible simple descriptivism.

Note that our appeal to simple descriptivism is compatible with a second-order, knowledgebased analysis of epistemic modals. For example, the concept of knowledge might be analyzed in terms of unGettiered (or nonaccidental) justified, true belief. Clearly, however, one would not need to have all of these concepts in order to have a concept of knowledge. Similarly, might might be analyzed in terms of compatible with what I know (second-order, epistemic concepts). It does not follow that Fido must have the latter concepts in order to have the former. ${ }^{41}$

In summary, it is plausible that young children and some animals can possess the concepts needed in order to form modal-beliefs. ${ }^{42}$ Furthermore, our assumption of descriptivism does not prevent us from using Yalcin's Fido example in support of this claim.

\section{4.b The oversophistication objection, pt. 2: extremely simple creatures}

Frankish could insist that a sufficiently young child or simple animal is unable to form modalbeliefs. Peter Carruthers (2006, 65-83) has argued on the basis of empirical research that bees are guided by simple belief and desire combinations. Perhaps they have beliefs with contents such as that the nectar is over there or the hive is that way. Supposing he is right, it seems unlikely that they have modal-beliefs; they do not believe that the nectar is probably over there. And even if bees do not

\footnotetext{
${ }^{40}$ Yalcin is assuming a knowledge-based analysis of epistemic modals; however, the success of the objection does not depend on this. For example, Fido also doesn't believe that $I$ will receive a bone is consistent with his total evidence (evidence-based analysis).

${ }^{41}$ Moon $(2018,1840)$ makes a similar argument in response to Yalcin.

${ }^{42}$ Dogramaci $(2018,10)$ also notes that he is willing to liberally attribute modal concepts to unsophisticated creatures in response to over-sophistication worries; he cites Hawthorne and Stanley $(2008,585)$ and Weisberg $(2013,10)$ on this point.
} 
have beliefs, there is plausibly some animal, $A$, that is sophisticated enough to believe that $\mathrm{X}$ is over there but not sophisticated enough to believe that X might be over there or X is probably over there. ${ }^{43}$

However, once we imagine a creature that is so simple that it is only guided by very basic beliefdesire combinations, then it is no longer clear that it has credences. The doxastic attitudes it uses to guide its behaviors would just be on-off belief states, not mental states that come in degrees, like credences.

In response, Frankish might appeal to empirical evidence that some simple creatures behave probabilistically. ${ }^{44}$ Consider a revision of Yalcin's case above. Suppose Fido is more likely to go to Fred for food than Wilma, but will go to Wilma if Fred is not around. (We can imagine that Fred has given Fido food about twice as often as Wilma has.) It seems that this behavior is explained by Fido's having a higher credence that Fred will give him food than that Wilma will, even though he doesn't believe that Fred is more likely to give him food because he doesn't have the concept of probability.

Or, consider a version of the case of the bees above. Suppose there are two locations that sometimes have nectar: one that almost always has nectar (let's say, roughly $9 / 10$ times) and another that sometimes has nectar (let's say, roughly $5 / 10$ times). The bees might exhibit the following sort of probabilistic behavior: always check for nectar at the first location, and then, if nectar isn't available, check the second location. ${ }^{45}$ This behavior might suggest the bees have credences even though they don't have the concept of probability.

Our response involves the common distinction between behaviors caused by beliefs or credences of a person and behaviors caused by subpersonal representations of the person. If I unknowingly lean my hand against a hot stove, my body will immediately react and pull it away. I didn't initially know (or believe or have confidence) that my hand was touching a hot and damaging object until I looked, even if my central nervous system, activated by nerves in my hand, in some sense had the content the hand is touching a hot and damaging object. The behavior was caused by subpersonal representations and not by $m y$ believing or being confident that my hand had touched a hot stove. This paper is about how beliefs and credences of persons (or believers or subjects) relate to each other, not how subpersonal representations in bodies-e.g., one's brain or nervous system-relate to each other. ${ }^{46}$ (Note also, as Lyons $[2016,250]$ points out, that a belief (or credence) being unconscious does not imply it is subpersonal. I still unconsciously believe and am confident of things, such as what my name is, even when I am dreamlessly asleep.)

With that in mind, we suggest two interpretations of the creatures' probabilistic behavior. First, some creatures (like bees or other insects, for instance) might have only subpersonal (or subanimal) mechanisms that cause them to check the place that almost always has nectar first, and then go to the place that only sometimes has nectar. True, it doesn't seem correct to say that the bee believes that one location is more likely to have honey than another location. However, it also doesn't seem correct to say that the bee is more confident, or has more confidence, that the honey is in one location

\footnotetext{
${ }^{43}$ For argument that this is at least metaphysically possible, see Moon $(2019,281-84)$.

${ }^{44}$ See Balci, Freestone, and Gallistel (2009), Kheifets and Gallistel (2012), and the next footnote. For philosophical discussion of these types of cases, see Jeffrey $(1985,484)$ and Carruthers (2006).

${ }^{45}$ For relevant empirical research on honeybees, see Gould and Gould (1995) and Tatuz et al. (2004).

${ }^{46}$ Might some Bayesians say that subpersonal probabilistic representations are what they're interested in when they use "credence" talk? Some might, although we take mainstream discussions about the relationship between belief and credence to be about attitudes of the person, not something subpersonal. Here are two reasons for thinking this. First, when philosophers explain "credence" talk, they illustrate it by using instances of a person having confidence in a proposition, not anything subpersonal (see Moon [2019, 276-77] for a list of quotes). Second, philosophers interested in credences are interested in something that is rationally evaluable. But subpersonal representations do not meet this condition because, as Smithies (2019, 121-24) argues, they are not held for, or responsive to, reasons. (Lyons [2016, 247-55] makes a similar argument.) Lastly, even if philosophers' use of "credence" doesn't definitely pick out something personal or subpersonal, we will just say that our project is about the person-level attitudes, not subpersonal representations. Thanks to a referee for the question and for helping us see the need to clarify these points.
} 
than the other. ${ }^{47}$ The bee has neither a modal-belief nor a credence, and this is because its behavior is best explained by subpersonal (or subanimal) mechanisms. In other cases, such as the Fido case, the creatures may actually have probabilistic concepts. It seems correct that Fido thinks that Fred is more likely to give him food than Wilma. ${ }^{48}$ But in these cases, it also seems that the creature has varying degrees of confidence.

Now, we do not want to take a stand on which creatures (e.g., Fido or the bees) do have probabilistic concepts; that would require a more careful empirical argument. Rather, our thought is this. Insofar as we are inclined to say that a creature has some degree of confidence, we are also inclined to say that they also have simple probabilistic concepts (and modal-beliefs). And insofar as we are inclined to say that the creature's cognitive mechanisms are so unsophisticated that it doesn't even have simple probabilistic concepts, we are also inclined by that lack of sophistication to think that the creature's behaviors are explained by subpersonal mechanisms. We make these claims about what seems metaphysically tied to what without committing to any empirical claims about dogs or bees.

To summarize our response to the oversophistication objection, in the previous section, we argued that children and sophisticated animals who clearly exhibit varying degrees of confidence also seem to have modal-beliefs-such beings pose no problem for Belief-First. In this section, we argued that extremely simple creatures exhibit behaviors that fall under two categories: (a) their behaviors are explained by basic belief-desire pairs, or (b) their behaviors are explained by probabilistic subpersonal mechanisms. In neither case do we posit a credence without a modalbelief, and so there is no clear counterexample.

We close by making explicit some of the fruits of this discussion. We have drawn out implications of Belief-First that make clear what it would take for there to be a successful counterexample. It would require showing either that an animal like Fido doesn't have simple concepts like might (and not just that Fido doesn't have second-order concepts), or that some of these extremely simple animals' probabilistic behaviors are explained by mental states of the animal, not the subpersonal (or subanimal) mechanisms. Given that we have shown that there's a lot to say in favor of Belief-First in the previous sections, we do not take accepting the relevant implications to be a hard bullet to bite (e.g., that bees' probabilistic behavior is explained by subpersonal mechanisms). However, we believe that further research should be aimed at exploring these cases.

\section{4.c Belief in multiple probabilities}

In this section, we discuss two potential counterexamples, motivated by Staffel's $(2013,3537)$ earlier objection, quoted at the beginning of section 2.b (see also Easwaran $[2015,659]$ ). The first has an obvious reply, but it sets the stage for a more challenging one. Suppose Fred believes that Goldbach's conjecture - that every integer greater than two is the sum of two primes-has a probability of either 1 or 0 . It seems possible that Fred could have a 0.5 credence that Goldbach's conjecture even though Fred does not believe the probability is 0.5 ; he thinks it's either 1 or 0 . Hence, we have a counterexample to Biconditional.

This proposed counterexample fails. Fred thinks the objective probability is either 1 or 0 (since it's either metaphysically necessary or impossible). But it's also natural to think that Fred will think that, given his evidence, the conjecture is as likely to be true as it is to be false. Hence, he believes the epistemic probability is 0.5 , which corresponds to his 0.5 confidence.

Here's a more challenging counterexample. ${ }^{49}$ Suppose Sally is unsure of whether her evidence supports $p$. After some reflection, she comes to think that either $p$ is very probable on her evidence

\footnotetext{
${ }^{47}$ Cf. Moon $(2019,284)$.

${ }^{48}$ See Balci, Freestone, and Gallistel $(2009,2459)$ and Crary (2012) for some relevant empirical research.

${ }^{49}$ Thanks to the audience at the "What Are Degrees of Belief" conference, especially Jason Konek, for raising this objection and for helpful discussion.
} 
or very improbable on her evidence, but she isn't sure which; her evidence is very complicated. (Perhaps a trustworthy genie told Sally that her complicated evidence either strongly confirms $p$ or strongly disconfirms $p$.) In this case, Sally believes the probability of $\mathrm{p}$ is either very low or very high; more importantly, she doesn't believe that the probability, given her evidence, is 0.5. Furthermore, her belief is about epistemic probability. Earlier, we argued that belief in an epistemic probability does not entail beliefs about one's evidence (entertaining an analysandum does not entail entertaining each analysans), but surely one could form a belief about an epistemic probability on the basis of one's belief about the evidence. But it seems possible that Sally has a middling credence $(\sim 0.5)$ in $p$. Hence, Biconditional is false.

In response, on a natural reading of the case, what Sally is unsure about is what her first-order evidence supports. Her second-order evidence about what her first-order evidence supports, because the first-order evidence is so complicated, leads her to think that it either very strongly supports $p$ or very strongly supports $\sim p$. But then it seems that her overall evidence, including both first-order and second-order evidence, equally supports believing $p$ as it does believing $\sim p$. But then Sally will naturally think that the epistemic probability of $p$, given her total evidence, is about 0.5 . And this is what her credence is.

An alternative reading of the case is that Sally actually does not have a middling credence in $p$. However, because her evidence is so complicated, Sally accepts-assumes for the sake of actionthat the probability of $p$ is 0.5 ; she can't treat it as both high and low at the same time. However, acting as if the probability of $p$ is 0.5 doesn't mean that her credence is $0.5-$ she is acting as if the probability is 0.5 for practical reasons. On either reading, the counterexample fails. ${ }^{50}$

\section{Conclusion}

We've argued for a belief-first view of the relationship between belief and credence. First, we explained and developed a plausible belief-first view. Then, we gave a number of arguments for it. Finally, we responded to two objections to it. We conclude that the belief-first view is more plausible than many have previously supposed.

Acknowledgments. Both authors regard each other as equal collaborators and cowriters of this paper. Moon's name appears first since he actually believes the view, and it is a central part of his research agenda. Jackson has written a number of papers defending dualism and has other works in progress attacking belief-first views. Perhaps Moon will help Jackson cowrite one or two of those papers, but don't count on it! But, if so, Jackson's name will come first in those papers. We would like to thank Sinan Dogramaci, Ben Lennertz, Peter Markie, Matthew McGrath, Andrew Melnyk, Paul Weirich, and an anonymous referee from this journal for helpful comments on earlier drafts. Thanks also to the Notre Dame epistemology reading group (2016-2017), the audience at the 2018 "What Are Degrees of Belief" conference in Leeds, especially Ed Elliott, for helpful comments and feedback.

Andrew Moon's areas of interest are in epistemology, philosophy of mind, and philosophy of religion. He has recently written on the natures of belief and confidence, religious epistemology, memory, the internalism/externalism debate, and evolutionary debunking arguments. He is currently an assistant professor at Virginia Commonwealth University.

Liz Jackson is a research fellow at Australian National University and an assistant professor at Ryerson University. She has published work on the belief-credence connection, epistemic permissivism, and pragmatic/moral encroachment. Her research interests also include social epistemology, decision theory, and philosophy of religion. She completed her PhD at Notre Dame.

\section{References}

Adler, J. 2002. Belief's Own Ethics. Cambridge, MA: MIT Press.

Andrews, K. 2015. The Animal Mind: An Introduction to the Philosophy of Animal Cognition. New York: Routledge.

\footnotetext{
${ }^{50}$ Thanks to Ben Lennertz for suggesting this alternative reading.
} 
Andrews, K. 2016. “Animal Cognition.” In The Stanford Encyclopedia of Philosophy (Summer 2016), edited by Edward N. Zalta. https://plato.stanford.edu/archives/sum2016/entries/cognition-animal.

Archer, S. 2018. “Why 'Believes’ Is Not a Vague Predicate.” Philosophical Studies 175: 3029-48.

Balci, F., D. Freestone, and C. R. Gallistel. 2009. "Risk Assessment in Man and Mouse.” The Proceedings of the National Academy of Sciences of the United States of America 6 (7):2459-63.

Beck, J. 2012. “Do Animals Engage in Conceptual Thought?” Philosophy Compass 4: 756-67.

Bouvens, L., and J. Hawthorne. 1999. "The Preface, the Lottery, and the Logic of Belief." Mind 108: 241-64.

Buchak, L. 2015. "Belief, Credence and Norms." Philosophical Studies 169: 285-311.

Carruthers, P. 2006. The Architecture of the Mind. Oxford: Clarendon Press.

Carter, J. A., B. Jarvis, and K. Rubin. 2016. “Belief without Credence.” Synthese 193: 2323-51.

Christensen, D. 2004. Putting Logic in Its Place. Oxford: Oxford University Press.

Churchland, P. M. 1981. “Eliminative Materialism and the Propositional Attitudes.” The Journal of Philosophy 78: 67-90.

Clarke, R. 2013. "Belief Is Credence One (in Context).” Philosophers' Imprint 13: 1-18.

Collins, J. Forthcoming. "Simple Belief." Synthese.

Crabill, J. 2013. "Suppose Yalcin Is Wrong about Epistemic Modals.” Philosophical Studies 162: 625-35.

Crary, A. 2012. "Dogs and Concepts." Philosophy 87 (2): 215-73.

Davidson, D. 1982. "Rational Animals." Dialectica 36: 318-27.

DeRose, K. 1991. "Epistemic Possibilities." The Philosophical Review 100: 581-605.

Dogramaci, S. 2018. "Rational Credence through Reasoning." Philosophers' Imprint 18: 1-25.

Dogramaci, S. 2016. "Knowing Our Degrees of Belief." Episteme 13: 269-87.

Dorr, C., and J. Hawthorne. 2013. “Embedding Epistemic Modals.” Mind 122: 867-914.

Dorst, K. 2019. “Lockeans Maximize Expected Accuracy.” Mind 128: 175-211.

Dougherty, T., and P. Rysiew. 2009. "Fallibilism and Concessive Knowledge Attributions." Philosophy and Phenomenological Research 78: 123-32.

Douven, I., and T. Williamson. 2006. “Generalizing the Lottery Paradox.” The British Journal for the Philosophy of Science 57 (4): 755-79.

Dummett, M. 2010. The Nature and Future of Philosophy. New York: Columbia University Press.

Easwaran, K. 2015. "Formal Epistemology." The Journal of Philosophical Logic 44: 651-62.

Easwaran, K. 2016. "How I Learned to Stop Worrying and Love Bayesian Probabilities." Noûs 50 (4): 1-38.

Elga, A. 2010. "Subjective Probabilities Should Be Sharp." Philosophers' Imprint 10: 1-11.

Foley, R. 1993. Working without a Net: A Study of Egocentric Epistemology. New York: Oxford University Press.

Foley, R. 2009. “Introduction.” In Degrees of Belief: An Anthology, edited by Franz Huber and Christoph Schmidt-Petri, 1-33. New York: Springer.

Frankish, K. 2004. Mind and Supermind. Cambridge: Cambridge University Press.

Frankish, K. 2009. "Partial Belief and Flat-Out Belief." In Degrees of Belief, edited by Franz Huber and Christoph Schmidt-Petri, 75-96. New York: Springer.

Friedman, J. 2013. "Rational Agnosticism and Degrees of Belief.” In Oxford Studies in Epistemology 4, edited by Tamar Szabó Gendler and John Hawthorne, 57-81. Oxford: Oxford University Press.

Ganson, D. 2008. "Evidentialism and Pragmatic Constraints on Outright Belief.” Philosophical Studies 193: 441-58.

Gertler, B. 2011. Self-Knowledge. New York: Routledge.

Gould, J. L., and C. G. Gould. 1995. The Honey Bee. 2nd ed. New York: W. H. Freeman.

Greco, D. 2015. “How I Learned to Stop Worrying and Love Probability 1.” Philosophical Perspectives 29: 179-201.

Harman, G. 1986. Change in View. Cambridge, MA: MIT Press.

Harman, G. 2008. "A Change in View: Principles of Reasoning." In Reasoning: Studies of Human Inference and its Foundations, edited by Jonathan Adler and Lance Rips, 35-47. Cambridge: Cambridge University Press.

Hawthorne, James. 2009. “The Lockean Thesis and the Logic of Belief." Degrees of Belief: An Anthology, edited by Franz Huber and Christoph Schmidt-Petri, 49-74. New York: Springer.

Hawthorne, John, and J. Stanley. 2008. Knowledge and Action. Journal of Philosophy, 105 (10): 571-90.

Holton, R. 2008. "Partial Belief, Partial Intention." Mind 117: 27-58.

Holton, R. 2014. "Intention as a Model for Belief." In Rational and Social Agency: Essays on the Philosophy of Michael Bratman, edited by Manuel Vargas and Gideon Yaffe, 12-33. Oxford: Oxford University Press.

Horgan, T. 2017. “Troubles for Bayesian Formal Epistemology.” Res Philosophica 94 (2): 23-55.

Huemer, M. 2007. "Epistemic Possibility.” Synthese 156: 119-42.

Jackson, E. 2018. “A Defense of Belief-Credence Dualism.” In The Proceedings of the Fifth Conference of the Brazilian Society of Analytic Philosophy, edited by João Luis Pereira Ourique, 77-78. Pelotas, Brazil: Série Dissertatio de Filosofia.

Jackson, E. 2019a. "Belief and Credence: Why the Attitude-Type Matters." Philosophical Studies 176 (9): 2477-96.

Jackson, E. 2019b. “How Belief-Credence Dualism Explains Away Pragmatic Encroachment." The Philosophical Quarterly 69 (276): 511-33.

Jackson, E. Forthcoming. "Belief, Credence, and Evidence.” Synthese. 
Jeffrey, R. 1970. “Dracula Meets Wolfman: Acceptance vs. Partial Belief.” In Induction, Acceptance, and Rational Belief, edited by Marshall Swain, 157-85. Dordrecht, Nether.: Reidel.

Jeffrey, R. 1985. “Animal Rationality.” In Actions and Events: Perspectives on the Philosophy of Donald Davidson, edited by E. LePore and B. P. McLaughlin. Oxford: Blackwell.

Joyce, J. M. 2002. "Levi on Causal Decision Theory and the Possibility of Predicting One's Own Actions." Philosophical Studies 110: 69-102.

Kaplan, M. 1996. Decision Theory as Philosophy. Cambridge: Cambridge University Press.

Kauss, D. Forthcoming. "Credence as Doxastic Tendency." Synthese.

Kheifets, A., and C. F. Gallistel. 2012. "Mice Take Calculated Risks." The Proceedings of the National Academy of Sciences of the United States of America, 109 (22): 8776-79.

Kratzer, A. 1977. "What 'Must' and 'Can' Must and Can Mean.” Linguistics and Philosophy 1: 337-55.

Lance, M. N. 1995. "Subjective Probability and Acceptance." Philosophical Studies 77 (1): 147-79.

Lee, M. 2017. "Credence and Correctness: In Defense of Credal Reductivism.” Philosophical Papers 46 (2): 273-96.

Leitgeb, H. 2013. Reducing Belief Simpliciter to Degrees of Belief. Annals of Pure and Applied Logic 164 (12): 1338-89.

Lennertz, B. Forthcoming. "Noncognitivism and the Frege-Geach Problem in Formal Epistemology." Philosophy and Phenomenological Research.

Levi, I. 1991. The Fixation of Belief and Its Undoing: Changing Beliefs through Inquiry. Cambridge: Cambridge University Press. Lewis, D. 1980. "A Subjectivist's Guide to Objective Chance." In Studies in Inductive Logic and Probability, edited by R. C. Jeffrey. Berkeley, CA: University of Berkeley Press.

Littlejohn, C. 2015. “Who Cares about What You Accurately Believe?” Philosophical Perspectives 29 (1): 217-48.

Lin, H. 2013. "Foundations of Everyday Practical Reasoning." Journal of Philosophical Logic 42: 831-62.

Lurz, R., ed. 2009. The Philosophy of Animal Minds. Cambridge: Cambridge University Press.

Lurz, R. 2019. “Animal Minds.” In The Internet Encyclopedia of Philosophy. https://www.iep.utm.edu/ani-mind.

Lyons, J. 2016. “Unconscious Evidence.” Philosophical Issues 26: 243-62.

Maher, P. 1993. Betting on Theories. Cambridge: Cambridge University Press.

Merricks, T. 2015. Propositions. New York: Oxford University Press.

Miller, D. 1966. “A Paradox of Information.” British Journal for the Philosophy of Science 17: 59-61.

Moon, A. 2017. "Beliefs Do Not Come in Degrees." Canadian Journal of Philosophy 47: 760-78.

Moon, A. 2018. “The Nature of Doubt and a New Puzzle about Belief, Doubt, and Confidence." Synthese 195: 1827-48.

Moon, A. 2019. “A New Puzzle about Belief and Credence." The Canadian Journal of Philosophy 49 (2): 272-91.

Moss, S. 2013. "Epistemology Formalized.” The Philosophical Review 122 (1): 1-43.

Moss, S. 2018. Probabilistic Knowledge. Oxford: Oxford University Press.

Otte, R. 2006. "Counterfactuals and Epistemic Probability." Synthese 152 (1): 81-93.

Pettigrew, R. 2015. “Accuracy and the Credence-Belief Connection.” Philosophers' Imprint 15 (16): 1-20.

Plantinga, A. 1993a. Warrant: The Current Debate. New York: Oxford University Press.

Plantinga, A. 1993b. Warrant and Proper Function. New York: Oxford University Press.

Pollock, J. 1983. "Epistemology and Probability." Synthese 55 (2): 231-52.

Ramsey, F. 1931. Truth and Probability. London: K. Paul, Trench, Trubner.

Ross, J., and M. Schroeder. 2014. "Belief, Credence and Pragmatic Encroachment." Philosophy and Phenomenological Research 88: 259-88.

Rothschild, D. 2012. “Expressing Credences." Proceedings of the Aristotelian Society 112: 99-114.

Schiffer, S. 2003. The Things We Mean. Oxford: Oxford University Press.

Schnieder, B. 2010. "Expressivism Concerning Epistemic Modals.” The Philosophical Quarterly 60: 601-15.

Schwitzgebel, E. 2008. “The Unreliability of Naive Introspection.” Philosophical Review 117: 245-73.

Silk, A. 2017. "How to Embed an Epistemic Modal: Attitude Problems and Other Defects of Character." Philosophical Studies 174: 1773-99.

Smith, M. 2010. “A Generalized Lottery Paradox for Infinite Probability Spaces.” The British Journal for Philosophy of Science 61: 821-31.

Smithies, D. 2012. “The Normative Role of Knowledge.” Noûs 46 (2): 265-88.

Smithies, D. 2019. The Epistemic Role of Consciousness. New York: Oxford University Press.

Sosa, E. 2011. Knowing Full Well. Princeton, NJ: Princeton University Press.

Staffel, J. 2013. “Can There be Reasoning with Degrees of Belief?” Synthese 190: 3535-51.

Staffel, J. 2017. “Accuracy for Believers.” Episteme 14 (1): 39-48.

Staffel, J. 2019. “How Do Beliefs Simplify Reasoning?” Nô̂s 53 (4): 937-62.

Stanley, J. 2005. "Fallibilism and Concessive Knowledge Attributions." Analysis 65: 126-31.

Stich, S. 1979. “Do Animals Have Beliefs?” Australasian Journal of Philosophy 57: 15-28.

Stich, S. 1996. Deconstructing the Mind. Oxford: Oxford University Press.

Sturgeon, S. 2008. "Reason and the Grain of Belief." Noûs 42: 139-65. 
Sturgeon, S. 2010. “Confidence and Coarse-Grained Attitudes.” In Oxford Studies in Epistemology, edited by Tamar Gendler and John Hawthorne, 126-49. Oxford: Oxford University Press.

Sturgeon, S. 2020. The Rational Mind. Oxford: Oxford University Press.

Swanson, E. 2011. "How Not to Theorize about the Language of Subjective Uncertainty." In Epistemic Modality, edited by A. Egan and B. Weatherson, 249-69. Oxford: Oxford University Press.

Tautz, J., Zhang, S. W., Spaethe, J., Brockmann, A., Si, A., and Srinivasan, M. V. 2004. "Honeybee Odometry: Performance in Varying Natural Terrain.” PLoS Biology 2: 915-23.

Weatherson, B. 2005. “Can We Do Without Pragmatic Encroachment?” Philosophical Perspectives 19: 417-43.

Wedgwood, R. 2012. "Outright Belief." Dialectica 66: 309-29.

Weisberg, J. 2013. "Knowledge in Action.” Philosopher's Imprint 13 (22): 1-23.

Weisberg, J. Forthcoming. "Belief in Psyontology.” Philosophers' Imprint.

White, R. 2010. "Evidential Symmetry and Mushy Credence." In Oxford Studies in Epistemology, edited by T. Gendler and John Hawthorne, 161-86. Oxford: Oxford University Press.

Williamson, T. 2000. Knowledge and Its Limits. Oxford: Oxford University Press.

Yalcin, S. 2011. "Nonfactualism about Epistemic Modality." In Epistemic Modality, edited by A. Egan and B. Weatherson, 295-332. Oxford: Oxford University Press.

Cite this article: Moon, A. and Jackson, E. 2020. Credence: A Belief-First Approach. Canadian Journal of Philosophy 50: 652-669, doi:10.1017/can.2020.9 